\title{
Technologie in der Pflege: Ein Muss für die Zukunft
}

\author{
Karin Frick
}

Keine andere Industrienation altert so schnell wie Japan - und verzichtet zugleich freiwillig auf Immigration. In Japan fehlen im 2020 voraussichtlich 400000 Fachkräfte im Pflegebereich. Um diese Lücke zu schliessen, setzen die Japaner verstärkt auf Roboter, welche Dank verbesserter Feinmotorik und emotionaler Intelligenz auch für anspruchsvollere Pflegeaufgaben voll einsatzfähig sein werden. Vor einem Jahr wurde in Japan die Roboterdame Aiko Chihira vorgestellt. Sie ist lebensgross und hat eine menschliche Anmutung und soll künftig als Kommunikationsroboter am Empfang oder im sozialen Bereich eingesetzt werden.

\section{Technologie et soins : un plus pour l'avenir}

Aucun autre pays industrialisé ne vieillit aussi rapidement que le Japon et ne renonce simultanément volontairement à l'immigration. Selon les prévisions, le Japon connaîtra en 2020 un déficit de 400000 employés qualifiés dans le domaine des soins. Afin de combler ce vide, les Japonais misent fortement sur les robots qui, grâce à une motricité fine améliorée et à une intelligence émotionelle, seront également pleinement opérationnels pour les tâches de soins exigeantes. Il y a de cela un an, la femme robot Aiko Chihira a été présentée au Japon : grandeur nature, elle possède une apparence humaine et doit à l'avenir être utilisée comme robot de communication à l'accueil ou dans le domaine social.

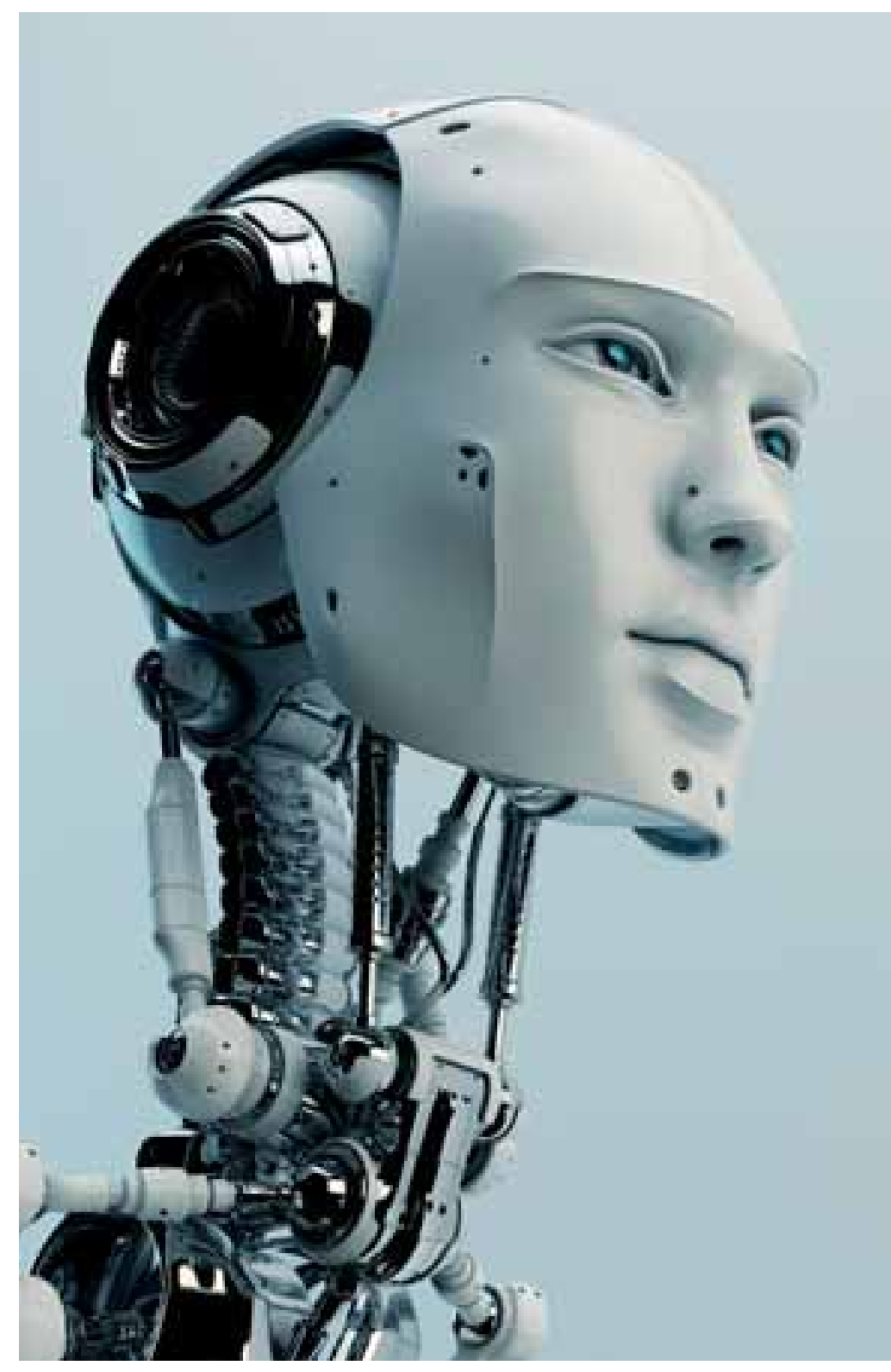

DOI 10.1024/2297-5160/a000047

\section{Roboter in der Pflege}

Der Einsatz der Roboter in der Pflege ist unvermeidlich. Pflegearbeit ist hart - physisch und psychisch. Manchmal gefährlich und emotional erschöpfend. Verlangt zeitlich hohe Präsenz. Pflegearbeit kann man nicht einfach beschleunigen. Stellen Sie sich dagegen einen Roboter-Pfleger vor: Er wird nicht müde, ist immer da und verfügbar

wann immer er gebraucht wird. Wenn sein Patient schläft, ist der Roboter-Pfleger immer wach und macht Wäsche und Haushalt. Wenn die Pflegeperson aufwacht, wird sie mit einer freundlichen Stimme begrüsst. Der Roboter hilft ihr aus dem Bett und auf die Toilette. Der Roboter hilft die Medikamente zu nehmen und beim Frühstück weiss er welche Fragen sein/e Klient/in haben wird und wie sie am besten zu beantworten sind ... 


\section{Ist das unmenschlich?}

Im Dienstleistungsbereich gibt es wenig Potential für ein Wachstum der Arbeitsproduktivität. Vor allem alte, «kinderlose» Gesellschaften werden gezwungen sein, Roboter für Pflegearbeit einzusetzen. Die Automatisierung der Pflege wird notwendig aus der Sicht der Jungen, weil menschliche Arbeitskraft zu teuer und zu knapp ist. Aus der Perspektive der Alten, weil sie einen Roboter selber steuern können und von einer überlasteten Pflegerin nichts als Druck zu erwarten haben - denn immer schneller pflegen geht nicht.

Die Akzeptanz der technischen Pflegesysteme hängt wesentlich davon ab, wer sie steuert: die Pflegebedürftigen, die Angehörigen, Google, die Versicherung oder die Sozialämter. Wir stehen noch am Anfang der Entwicklung. Heute sind viele Fragen offen, die Vor- und Nachteile der
Pflege-Technik müssen diskutiert werden. Doch dabei geht nicht um die Frage, ob wir in Zukunft smarte Maschinen in der Pflege einsetzen, sondern wo und wie. Technisch ist bald fast alles möglich. Welche Applikationen schliesslich Erfolg haben werden, ist heute noch offen, wie auch die Frage, wer das Netz für Assisted Living kontrollieren wird: der Nutzer/die Nutzerin, seine/ihre Familie oder eine höhere technische Intelligenz.

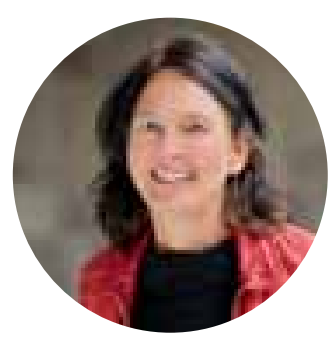

Karin Frick ist Ökonomin, Leiterin Research und Mitglied der Geschäftsleitung des Gottlieb Duttweiler Instituts.

karin.frick@gdi.ch

Lucerne University of

Applied Sciences and Arts

\section{HOCHSCHULE LUZERN}

Soziale Arbeit

Wirtschaft
Master of Advanced Studies

\section{MAS Altern und Gesellschaft}

\author{
Certificate of Advanced Studies
}

CAS Planung und Alter

CAS Märkte und Alter

CAS Soziale Systeme und Alter 